\title{
Knowledge Management System Konservasi Hutan Tanaman Mangrove
}

\author{
Dwina Admella Yudhanti ${ }^{\# 1}$, Eva Faja Ripanti ${ }^{\# 2}$, Anggi Perwitasari ${ }^{\# 3}$ \\ "Program Studi Informatika, Fakultas Teknik, Universitas Tanjungpura \\ Jl. Prof. Dr. H. Hadari Nawawi, Pontianak 78124 \\ ${ }^{1}$ dwinaadmella@gmail.com \\ evaripanti@untan.ac.id \\ 3anggiperwitasarieinformatika.untan.ac.id
}

\begin{abstract}
Abstrak - Hutan mangrove merupakan suatu ekosistem yang sumberdaya alamnya diarahkan untuk kesejahteraan manusia dan mewujudkan pemanfaatannya agar dapat berkelanjutan, maka ekosistem mangrove perlu dikelola dan dijaga keberadaannya. Knowledge Management System (KMS) menawarkan sebuah pendekatan yang saling terintegrasi dengan tujuan mengindentifikasi, menangkap, mengambil, membagi, dan mengevaluasi informasi. KMS membantu dalam pencarian, pemilihan, pengaturan, penyaringan dan penyajian informasi, kemudian memudahkan untuk memberikan pengetahuan dalam mengatur berjalannya proses kerja. Tujuan dilakukannya penelitian ini adalah membangun Knowledge Management System yang dapat membantu pengguna yaitu masyarakat, pemerintah dan peneliti dalam melakukan pelestarian mangrove. Metodologi penelitian yang dilakukan yaitu identifikasi masalah, analisis kebutuhan sistem, perancangan, implementasi, dan pengujian sistem. Penelitian ini mengadopsi sebuah framework yang memiliki empat proses yaitu analisis, strategi, perencanaan, dan strategi. Model pengembangan sistem menggunakan konsep System Development Life Cycle (SDLC). Pengujian sistem dilakukan dengan dua cara, yaitu pengujian Black Box dan User Acceptance Test (UAT). Hasil pengujian Black Box adalah sistem dapat bekerja dengan baik dalam menangani suatu kemungkinan kesalahan, sedangkan pada pengujian UAT sistem dinilai sudah memberikan hasil yang baik. Hasil kuesioner yang dilakukan $83.47 \%$ menyatakan aplikasi ini sangat membantu. Secara keseluruhan, KMS Hutan Tanaman Mangrove bisa membantu proses penyampaian informasi dan pengetahuan manajemen pengumpulan data.
\end{abstract}

Kata kunci- Knowledge Management System (KMS), Hutan Tanaman Mangrove, System Development Life Cycle (SDLC), Framework, User Acceptance Test (UAT)

\section{Pendahuluan}

Indonesia merupakan negara kepulauan yang salah satu sumberdaya alamnya ada di wilayah pesisir yaitu ekosistem hutan mangrove yang sangat potensial bagi kesejahteraan masyarakat baik dari segi ekonomi, sosial, dan lingkungan hidup namun semakin hari semakin kritis ketersediaanya [1].
Mangrove adalah vegetasi hutan yang tumbuh diantara garis pasang surut, sehingga hutan mangrove dinamakan juga hutan pasang. Hutan mangrove terdapat didaerah pantai yang terus menerus atau berurutan terendam dalam air laut dan dipengaruhi pasang surut, tanahnya terdiri atas lumpur dan pasir [2]. Hutan mangrove diarahkan untuk mewujudkan pemanfaatannya agar dapat berkelanjutan, maka ekosistem mangrove perlu dikelola dan dijaga keberadaannya.

Pengelolaan hutan mangrove memiliki dua konsep utama. Pertama, perlindungan hutan mangrove sebagai upaya melindungi hutan mangrove agar menjadi kawasan hutan mangrove konservasi. Kedua, rehabilitasi hutan mangrove dengan melakukan kegiatan penghijauan. Penghijauan adalah proses pembibitan mangrove, dimana bibit yang digunakan haruslah bibit yang terbaik sehingga tanaman dapat tumbuh dengan baik. Proses pembibitan ini harus dilakukan sesuai dengan langkah-langkah yang sebenarnya agar tidak terjadi kesalahan dalam proses pembibitan, karena jika terjadi kesalahan dalam proses pembibitan maka bibit tidak dapat tumbuh dengan baik atau mengalami kematian.

Permasalahan yang sedang terjadi sekarang terhadap hutan mangrove khususnya di Indonesia adalah terjadinya kerusakan akibat pemanfaatan yang melebihi kebutuhan. Faktor penyebab terjadinya kerusakan hutan mangrove yaitu pemanfaatan yang tidak terkontrol karena masyarakat yang menempati wilayah pesisir sangat tinggi dan konversi hutan mangrove yang dilakukan untuk berbagai kepentingan, misalnya untuk perkebunan, tambak, pemukiman, kawasan industri dan wisata tanpa mempertimbangkan kelestarian dan fungsinya terhadap lingkungan sekitar.

Kerusakan ini dapat mengakibatkan intrusi air laut atau masuknya air laut kearah daratan sehingga mengakibatkan mutu air tawar sumur/ sungai menurun bahkan menjadi payau atau asin [3]. Selain intrusi air laut kerusakan ini juga dapat mengakibatkan menurunnya keanekaragaman hayati di wilayah pesisir, meningkatnya aberasi pantai, dan meningkatnya pencemaran pantai. 
Knowledge Management System (KMS) menawarkan sebuah pendekatan yang saling terintegrasi dengan tujuan mengidentifikasi, menangkap, mengambil, membagi dan mengevaluasi informasi. Informasi tersebut meliputi database, dokumen, prosedur dan kebijakan. Penerapan knowledge management menggunakan model-model statis berupa data yang bersumber pada asumsi dari ilmu pengetahuan, program perangkat lunak. Hal tersebut juga meliputi pengetahuan baru yang bisa disimpan dalam database yang terkomputerisasi [4]. Alasan utama menggunakan Knowledge Management System (KMS) yaitu merupakan pendekatan sistematik yang membantu dalam pencarian, pemilihan, pengaturan, penyaringan dan penyajian informasi, kemudian memudahkan untuk memberikan pengetahuan dalam mengatur berjalannya sebuah proses kerja dan menambah pola pikir agar lebih kreatif dan inovatif. Karena pengetahuan yang sudah terstruktur dengan baik, maka akan lebih mudah dalam menggunakan pengetahuan tersebut sehingga akan menghemat waktu dan biaya.

Berdasarkan permasalahan diatas, proses pembibitan mangrove ini akan dipetakan dengan model knowledge management system (KMS) sehingga proses pembibitan akan berjalan sesuai dengan langkah-langkah yang dibuat. Keluaran yang diharapkan dari sistem ini adalah untuk membantu masyarakat dan pemerintah dalam rangka pengambilan keputusan terkait konservasi mangrove pada proses pembibitan guna melakukan pelestarian hutan tanaman mangrove.

\section{URAIAN PENELITIAN}

\section{A. Knowledge Management}

Knowledge Management merupakan suatu upaya untuk menghasilkan nilai dari intelektual organisasi melalui penciptaan, penyimpanan, penyebaran dan penerapan pengetahuan untuk mencapai tujuan. Knowledge Management adalah proses penerapan pendekatan sistematis untuk menangkap, menstruktur, mengelola dan menyebarkan pengetahuan agar dapat digunakan untuk bekerja lebih cepat. [4]. Knowledge Management memiliki dua jenis knowledge yaitu Explicit Knowledge dan Tacit Knowledge. Explicit Knowledge yaitu segala bentuk knowledge yang sudah direkam dan dikomentasikan sehingga lebih mudah untuk disampaikan dan dikelola. Tacit knowledge yaitu suatu pengetahuan yang terdapat di dalam pikiran atau yang melekat di dalam diri sesorang yang diperolehnya melalui pengalaman atau pekerjaannya [5].

1) Tacit Knowledge: Pengetahuan yang terdapat di dalam otak atau pikiran seseorang sesuai dengan pemahaman dan pengalaman orang itu sendiri. Biasanya pengetahuan ini tidak terstruktur, susah untuk didefinisikan dan diberitahukan dengan bahasa formal kepada orang lain dan isinya mencakup pemahaman pribadi. Pengetahuan ini umumnya belum terdokumentasi karena pengetahuan ini masih terdapat di dalam pikiran seseorang.

2) Explicit Knowledge: Pengetahuan yang sudah dikumpulkan serta diterjemahkan ke dalam suatu bentuk dokumentasi (rangkuman) sehingga lebih mudah dipahami oleh orang lain. Pengetahuan ini bersifat formal dan mudah untuk dibagikan ke orang lain dalam bentuk dokumentasi karena umumnya merupakan pengetahuan yang bersifat teori yang mempermudah seseorang dalam membagi pengetahuannya kepada orang lain melalui buku, artikel dan jurnal tanpa harus datang langsung untuk mengajari orang tersebut. Dalam proses penerapannya, pengetahuan explicit lebih mudah karena pengetahuan yang diperoleh dalam bentuk tulisan atau dokumentasi.

\section{B. Knowledge Management System (KMS)}

Knowledge Management System (KMS) adalah sistem yang dibangun dari Knowledge Management (KM) [6]. Knowledge Management System (KMS) merupakan teknologi yang memungkinkan KM untuk berjalan dengan efektif dan efisien [7].

Jadi pada dasarnya sebuah Knowledge Management System (KMS) adalah sistem pendukung dari Manajemen Pengetahuan. Peran KMS adalah membantu organisasi menjadi lebih efektif, KMS dapat menggantikan peran seseorang, ataupun membantu mempermudah pekerjaan yang dilakukan. Knowledge Management System (KMS) menawarkan sebuah pendekatan yang saling terintegrasi dengan tujuan mengidentifikasi, menangkap, mengambil, membagi dan mengevaluasi aset informasi kelompok. Informasi tersebut meliputi database, dokumen, prosedur dan sebagaimana yang merupakan bagian dari tiap-tiap anggota kelompok di dalam sebuah Sistem Manajemen Pengetahuan (Knowledge Management System) [4].

\section{Tanaman Hutan Mangrove}

Hutan mangrove adalah ekosistem hutan daerah pantai yang terdiri dari kelompok pepohonan yang bisa hidup dalam lingkungan berkadar garam tinggi. Salah satu ciri tanaman mangrove memiliki akar yang menyembul ke permukaan. Penampakan mangrove seperti hamparan semak belukar yang memisahkan daratan dengan laut. Kata mangrove berasal dari kata mangue (bahasa Portugis) yang berarti tumbuhan, dengan grove (bahasa Inggris) yang berarti belukar. Sementara itu dalam literatur lain disebutkan bahwa istilah mangrove berasal dari kata mangi-mangi (bahasa Melayu Kuno) [8].

Hutan mangrove adalah suatu kelompok jenis tumbuhan berkayu yang tumbuh di sepanjang garis pantai tropis dan subtropis yang terlindung dan memiliki semacam bentuk lahan pantai dengan tipe tanah anaerob. Penyebab utama hilangnya mangrove adalah konversi lahan untuk pertanian, permukiman dan infrastruktur pariwisata. Meski wilayah sebaran hutan mangrove cukup luas, hanya mangrove tropis yang memiliki densitas spesies tinggi. Lebih dari sepertiga luasan mangrove tropis ada di Asia Tenggara. Dari jumlah itu yang masuk wilayah Indonesia mencapai lebih dari $80 \%$. Sehingga Indonesia menjadi negara dengan hutan mangrove terluas [2]. Hutan mangrove memiliki peran yang besar bagi kehidupan manusia. Hutan ini memiliki banyak fungsi mulai dari penyedia sumber makanan, bahan baku industri, mencegah banjir, mencegah erosi, hingga fungsi rekreasi. 


\section{System Development Life Cycle (SDLC)}

System Development Life Cycle (SDLC) merupakan siklus pengembangan sistem dengan beberapa proses secara bertahap di dalam merancang dan mengembangkan sistem. SDLC memiliki tahapan dalam pengembangan sistem yaitu, perencanaan, analisis, perancangan, implementasi, dan perawatan (maintenance) [9].

\section{E. Pengujian Perangkat Lunak}

Pengujian yang dilakukan dalam penelitian ini sebagai tahap implementasi untuk menguji tingkat minimal kesalahan dan keakuratan perangkat lunak yang dirancang. Pengembang atau penguji perangkat lunak harus menyiapkan sesi khusus untuk menguji program yang sudah dibuat agar kesalahan maupun kekurangan dapat dideteksi dan dikoreksi secepatnya [10]. Adapun pengujian yang akan digunakan dalam penelitian yaitu pengujian sistem menggunakan pengujian black box dan UAT.

1) Pengujian Black Box: Metode pengujian Black Box dipilih karena metode pengujian tersebut tidak memperhatikan struktur logika internal (coding) dalam perangkat lunak. Pengujian Black Box yakni pengujian yang berfokus pada persyaratan fungsional sistem yang telah dibuat. Pada pengujian ini didasarkan pada detail aplikasi seperti tampilan aplikasi, fungsi-fungsi yang ada pada aplikasi, dan kesesuaian alur fungsi dengan proses yang diinginkan oleh pengguna. Pengujian ini tidak melihat dan tidak menguji source code program [11].

Uji coba Black Box berusaha untuk menemukan kesalahan dalam beberapa kategori, diantaranya :

- Fungsi-fungsi yang salah atau hilang

- Kesalahan interface

- Kesalahan dalam struktur data atau akses database eksternal

- Kesalahan performa

- Kesalahan inisialisasi dan terminasi

2) Pengujian User Acceptance Test (UAT): User Acceptance Test (UAT) merupakan pengujian yang dilakukan oleh end-user, pihak yang langsung berinteraksi dengan sistem dan dilakukan verifikasi apakah fungsi yang ada telah berjalan sesuai dengan kebutuhan [12]. Pengujian UAT dilakukan dengan menggunakan metode kuesinoer. Kuesioner adalah teknik pengumpulan informasi berupa sebuah daftar pertanyaan yang harus diisi oleh responden yang nantinya akan diukur. Penggunaan kuesioner ini adalah untuk mengetahui keberhasilan dalam pembuatan sistem yang kita peroleh dari tanggapan responden. Adapun tujuan penyusunan kuesioner adalah guna memperbaiki bagian-bagian yang kurang tepat.

Kuesioner yang dilakukan melibatkan beberapa responden yang kualifikasinya telah ditentukan berdasarkan kebutuhan pengujian sistem. Responden adalah masyarakat, pemerintah dan peneliti yang merupakan aktor yang terlibat dengan konservasi mangrove. Kuesioner yang dilakukan menggunakan perhitungan skala likert dan untuk menghitung persentase menggunakan rating scale.

TABEL I

SKOR PENILAIAN

\begin{tabular}{|l|l|l|}
\hline No & $\begin{array}{l}\text { Skor } \\
\text { Skala }\end{array}$ & \multicolumn{1}{c|}{ Kriteria } \\
\hline 1. & 5 & $\begin{array}{l}\text { Sangat mudah/ sangat sesuai/ sangat bagus/ sangat } \\
\text { baik/ sangat membantu/ sangat tepat/ sangat } \\
\text { memenuhi }\end{array}$ \\
\hline 2. & 4 & $\begin{array}{l}\text { Mudah/ sesuai/ bagus/ baik/ membantu/ tepat/ } \\
\text { memenuhi }\end{array}$ \\
\hline 3. & 3 & $\begin{array}{l}\text { Cukup mudah/ cukup sesuai/ cukup bagus/ cukup } \\
\text { baik/ cukup membantu/ cukup tepat/ cukup } \\
\text { memenuhi }\end{array}$ \\
\hline 4. & 2 & $\begin{array}{l}\text { Sulit/ kurang sesuai/ kurang bagus/ buruk/ kurang } \\
\text { membantu/ kurang tepat/ kurang memenuhi }\end{array}$ \\
\hline 5. & 1 & $\begin{array}{l}\text { Sangat sulit/ tidak sesuai/ tidak bagus/ sangat buruk/ } \\
\text { tidak membantu/ tidak tepat/ tidak memenuhi }\end{array}$ \\
\hline
\end{tabular}

Kemudian untuk menghitung analisis hasil kuesioner menggunakan rumus perhitungan rating scale. Perhitungan rating scale ditentukan dengan menggunakan rumus sebagai berikut:

$$
\text { Persentase }(\%)=\frac{\text { Eskor yang diperoleh }}{\text { Shor ideal }} \times 100 \%(2.1)
$$

\section{METODOLOGI PENELITIAN}

\section{F. Metodologi Penelitian}

Metodologi penelitian merupakan suatu perencanaan penelitian yang akan dilakukan secara sistematis dan ilmiah. Metodologi penelitian tersebut diilustrasikan pada Gambar 1 berikut:

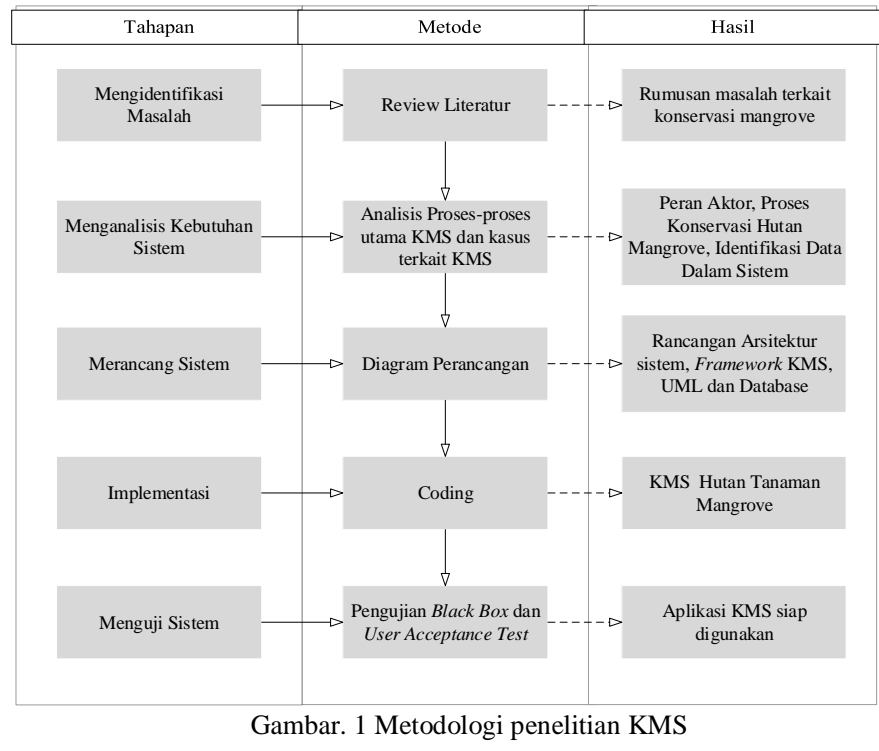

\section{G. Perancangan Arsitektur Sistem}

Arsitektur sistem merupakan penggambaran suatu perancangan sistem yang akan dibangun. Komponen sistem terdiri dari pengguna, data, dan informasi/proses, seperti pada Gambar 2. KMS ini di bangun berbasis website dan dapat diakses oleh masyarakat, peneliti, dan pemerintah. KMS 
memiliki dua jenis Knowledge yaitu Explicit Knowledge dan Tacit Knowledge. Dari kedua jenis knowledge, setiap informasi atau pengetahuan yang didapat terkait hutan tanaman mangrove akan disimpan ke dalam database. Pengguna juga dapat menambahkan data atau informasi terkait konservasi mangrove di web ini.

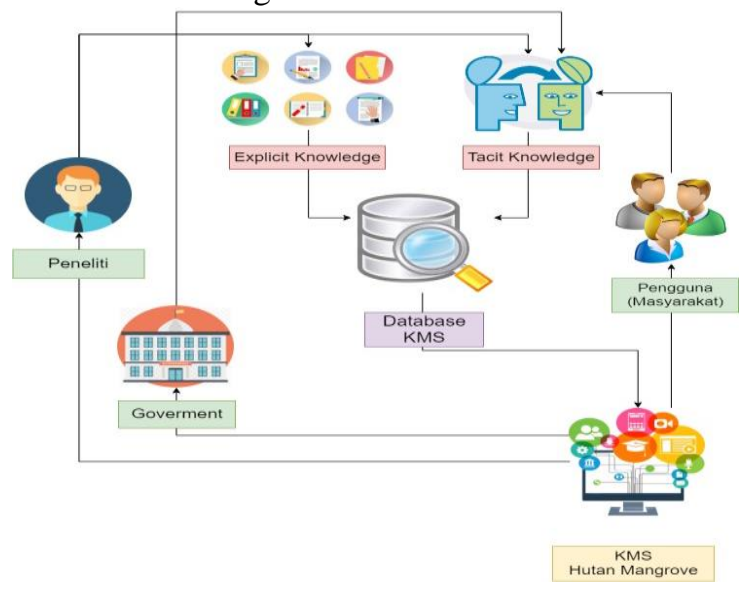

Gambar. 2 Arsitektur KMS hutan tanaman mangrove

\section{HASIL DAN ANALISIS}

\section{A. Hasil Penelitian}

Penelitian yang telah dilakukan berdasarkan 4 tahapan pada metodologi penelitian memberikan hasil pada setiap tahapan tersebut. Hasil Penelitian dapat dilihat pada Gambar 3 berikut. Berdasarkan penelitian yang telah dibuat, Penelitian ini menghasilkan beberapa poin penting. Hasil tersebut disampaikan berdasarkan Framework Knowledge Management System yang telah dibuat.

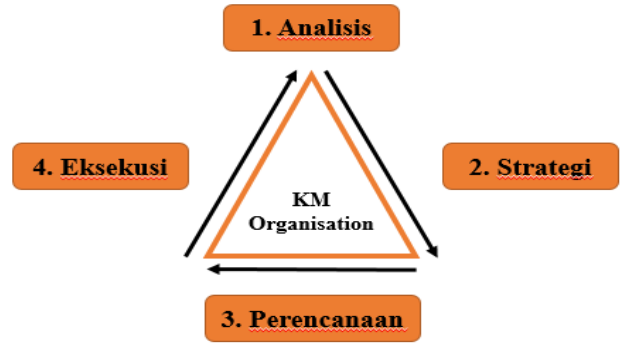

Gambar. 3 Framework knowledge management system

1) Analisis: Dalam tahap ini penulis menganalisis apa saja yang dilakukan pada konservasi mangrove. Pelestarian hutan mangrove dan memperbaiki hutan mangrove yang telah rusak diperlukan proses rehabilitasi dengan cara penanaman kembali tanaman mangrove [13]. Upaya pelestarian kembali hutan mangrove yang telah mengalami kerusakan dengan melakukan penanaman kembali terhadap hutan mangrove yang rusak melalui swadaya masyarakat untuk melakukan proses penanaman dibutuhkan bibit mangrove [14]. Oleh karena itu, dapat disimpulkan bahwa proses konservasi mangrove ini dilakukan dengan tiga tahapan yaitu pembibitan mangrove kemudian dilanjutkan dengan penanaman mangrove dan perawatan mangrove. Data pembibitan, penanaman dan perawatan didapat dari hasil studi literatur [15].

Mangrove umumnya tumbuh dalam 4 zona terdiri dari daerah terbuka yaitu bagian yang berhadapan dengan laut. Daerah tengah yaitu daerah yang memiliki sungai berair payau sampai hampir tawar, serta daerah ke arah daratan yang memiliki air tawar. Mangrove daerah terbuka di Idominasi jenis Sonneratia Alba dan Avicennia Alba. Mangrove daerah tengah, Zona ini terletak di belakang zona terbuka dan didominasi oleh jenis Rhizopora sp. Mangrove daerah payau, Zona ini biasanya didominasi oleh jenis Nypa atau Sonneratia. Mangrove daerah daratan : Jenis yang umum ditemukan pada zona ini termasuk Ficus microcarpus (F. retusa), N. fruticans, Lumnitzera racemosa, Pandanus sp. dan Xylocarpus moluccensis.

Jenis dan jarak tanam mangrove disesuaikan dengan lokasi salah satunya ialah penanaman di pinggir laut. Penanaman ini bertujuan untuk melindungi pantai dari abrasi atau sebagai jalur hijau jarak tanamnya $1 \times 1$ meter dengan jumlah bibit yang disesuaikan dengan kondisi pantai, lebih banyak bibit maka akan lebih baik.

Selain kebutuhan tiga tahapan di atas, proses konservasi mangrove juga melibatkan aktor-aktor yaitu masyarakat, pemerintah dan peneliti. Proses konservasi akan dilakukan secara langsung oleh masyarakat, dan pemerintah mengontrol berjalannya konservasi mangrove. Peneliti dapat menggunakan data-data tersebut untuk menambah pengetahuan dalam melakukan penelitian lebih lanjut mengenai konservasi mangrove. Selanjutnya, data dan peran aktor akan disatukan menjadi sebuah knowledge yang terintegrasi. Aktor-aktor yang terlibat di dalamnya memiliki peran masing-masing berdasarkan tacit knowledge dan explicit knowledge.

2) Strategi: Data yang digunakan dalam KMS ini ialah data tacit knowledge dan explicit knowledge. Data ini akan menjadi informasi yang penting untuk manajemen pengetahuan terkait proses konservasi mangrove, sehingga KMS hutan mangrove menjadi tepat untuk melakukan pengelolaan maupun manajemen kegiatannya. Metode yang digunakan dalam hal ini adalah dengan metode wawancara di mana kita dapat menanyakan terkait tiga proses besar konservasi. Metode lain yaitu dengan melihat dari sumber literatur, karena dari setiap literatur pasti terdapat suatu pendapat dari para ahli atau proses observasi yang telah dilakukan.

Data-data tersebut tersimpan di dalam database sistem, terdiri dari data pembibitan, penanaman, dan perawatan mangrove yang nantinya dapat diakses. Data tersebut akan menampilkan semua data yang terkait dengan keyword. Terdapat tiga bagian keyword di mana masing-masing terdiri dari sub keyword. Cara kerja pencarian keyword ini dengan mengolah keyword pada tahap ana lisis. Caranya adalah dengan mengkombinasikan keyword yang diinginkan. Misal, seorang peneliti ingin mengetahui cara melakukan pembibitan maka dapat menggunakan keyword pembibitan or bibit or jenis. Setiap inputan kata pencarian dipotong dengan karakter spasi sebagai pemisah. Contohnya "Jenis bibit mangrove“ dipotong menjadi ["Jenis", "bibit", "mangrove"]. 
Maka mesin pencari akan mencari dengan potongan kata tersebut, semua data yang memiliki kata yang sama dengan kata tersebut maka data akan muncul.

3) Perencanaan: KMS Konservasi Hutan Mangrove yang akan dibangun berupa perancangan model sistem informasi berbasis aplikasi komputer yang menyediakan kebutuhan informasi terkait konservasi mangrove. KMS ini dapat melakukan pengelolaan pengetahuan di sistemnya. KMS ini dibangun untuk memudahkan pencarian informasi dan pengumpulan informasi terkait mangrove kepada masyarakat, pemerintah dan peneliti sebagai user. Website ini berisikan informasi pembibitan, penanaman, perawatan, program pemerintah dan peraturan pemerintah yang dapat diakses pengguna. Gambaran awal sistem dapat dilihat pada Gambar 4

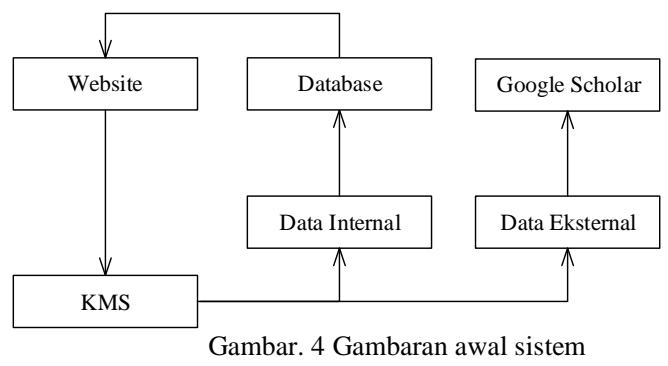

KMS konservasi hutan mangrove yang telah dirancang, memberikan pengetahuan Tacit dan Explicit yang digunakan dalam 2 tipe data yaitu data internal dan data eksternal. Data internal ini ialah data yang disediakan oleh sistem untuk menyimpan data tacit dan explicit. Data yang disediakan sistem dibatasi dari tahun 2016-2019, jika pengguna belum mendapatkan informasi yang dibutuhkan pada sistem maka dapat dialihkan ke data eksternal yaitu Google Scholar. Google Scholar merupakan salah satu mesin pencari yang menyediakan banyak informasi terkait data explicit sehingga dapat memenuhi kebutuhan pengguna dan agar lebih dinamis.

4) Eksekusi: Hasil dari perencanaan yang dilakukan adalah membangun sebuah website dengan upaya untuk mendukung berjalannya proses konservasi hutan mangrove, diperlukanlah KMS sebagai sistem yang dapat membantu proses konservasi. KMS tersebut menjadi suatu platform yang menghubungkan pengguna (masyarakat, pemerintah, peneliti) terhadap perannya dalam proses konservasi.

Pemerintah memiliki peran dalam melakukan pengelolaan terhadap sistem dan mengatur penyaringan pengetahuan. Misalkan pengguna lain menambahkan data artikel tentang perawatan pada sistem maka data yang telah ditambahkan masuk ke pemerintah dan menunggu persetujuan. Jika data disetujui maka akan terposting di halaman website. Selanjutnya, pengguna lain yaitu peneliti dan masyarakat yang juga dapat melakukan pengelolaan pengetahuan pada sistem ini. Peneliti dapat membagikan pengetahuannya, bentuk pengetahuan yang dikelola di antaranya dapat berupa file pengetahuan seperti artikel, dokumen, dan jurnal. Masyarakat dapat mengakses website untuk melihat informasi tentang mangrove dan juga dapat menambahkan data berupa artikel atau pengalaman selama mengelola mangrove pada sistem.

KMS menyediakan fitur pencarian untuk mengakses datadata penelitian yang terkumpul menjadi satu dalam sebuah database. Pencarian tersebut dapat menyaring informasi yang muncul berdasarkan keyword yang dimasukkan, selanjutnya menghubungkannya pada keyword lain yang masih berhubungan dalam satu tema.

\section{B. Perancangan Antarmuka Sistem}

Perancangan antarmuka (interface) dirancang sebagai gambaran awal sistem yang akan dibangun. Perancangan antarmuka sistem meliputi beberapa pengguna diantaranya masyarakat, pemerintah, peneliti, dan admin. Struktur antarmuka sistem dapat dilihat pada Gambar 5.

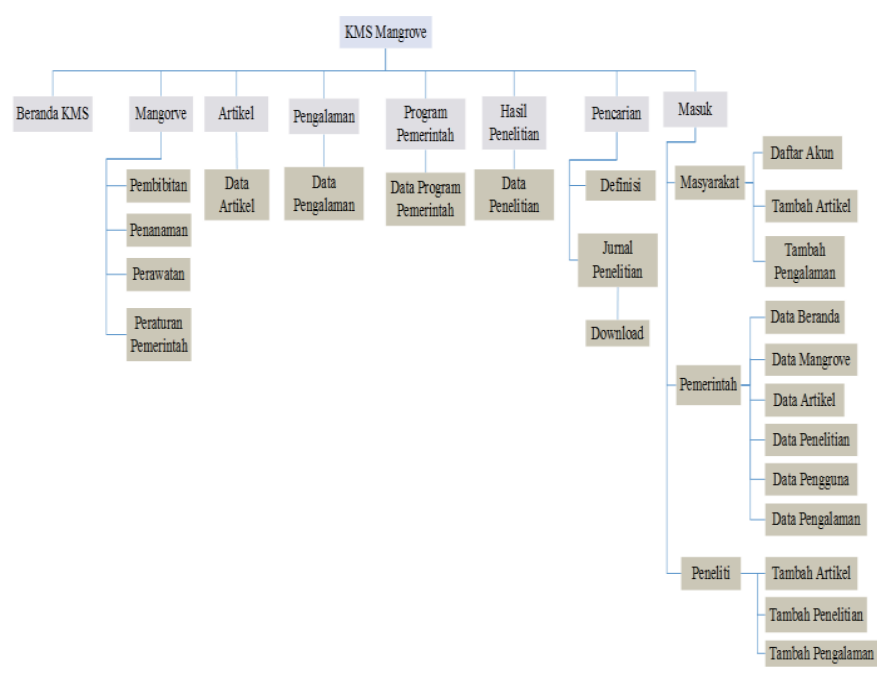

Gambar. 5 Struktur antarmuka sistem

\section{Hasil Perancangan}

Perancangan yang digunakan pada penelitian ini menggunakan tiga diagram digambarkan dalam bentuk class diagram untuk menggambarkan suatu struktur sistem yang akan dibangun dan hubungan antar tabel, use case diagram untuk mendeskripsikan fungsi apa saja yang ada di dalam sistem dan siapa saja yang berhak menggunakan fungsi-fungsi itu dan activity diagram untuk menggambarkan aktivitas yang dapat dilakukan oleh sistem bukan proses yang dilakukan aktor terhadap sistem. Ketiga diagram yang digambarkan akan menjelaskan seluruh proses didalam sistem. Perancangan tersebut menghasilkan sebuah KMS Konservasi Hutan Mangrove. Antarmuka dari KMS adalah antarmuka beranda, antarmuka log in, antarmuka masyarakat, antarmuka peneliti, dan antarmuka pemerintah sebagai administrator.

\section{Hasil Pengujian}

Pengujian pada KMS Konservasi Hutan Mangrove dilakukan dengan 2 jenis pengujian, yaitu pengujian black box untuk mengetahui hasil output sistem dan memeriksa fungsional dari sistem, serta pengujian UAT (User Acceptance Test) untuk mengetahui kelayakan sistem yang diuji oleh pengguna secara langsung dan berinteraksi dengan sistem untuk melihat fungsi yang ada jika telah berjalan sesuai dengan kebutuhan. 
1) Pengujian Black Box: Berdasarkan pengujian Black Box yang dilakukan pada KMS Konservasi Hutan Mangrove, saat dilakukan input data dengan keseluruhan data kosong, input salah satu data kosong, dan input data yang salah, maka terjadi kesalahan pada program.

Berikut ini adalah pengujian Black Box saat melakukan proses $\log$ in pada sistem dapat dilihat pada tabel 2.

TABEL III

HASIL UJI DATA LOG IN ATAU MASUK

\begin{tabular}{|c|c|c|c|}
\hline Fungsi & Kasus uji & $\begin{array}{c}\text { Hasil } \\
\text { Eksekusi }\end{array}$ & Keterangan \\
\hline \multirow{4}{*}{$\begin{array}{l}\text { Pengujian } \\
\text { Log in }\end{array}$} & $\begin{array}{l}\text { Nama pengguna } \\
\text { dan kata sandi } \\
\text { kosong }\end{array}$ & $\begin{array}{l}\text { Tidak } \\
\text { berhasil }\end{array}$ & $\begin{array}{l}\text { Menampilkan pesan } \\
\text { peringatan kesalahan: } \\
\text { "Bidang isian wajib } \\
\text { diisi" }\end{array}$ \\
\hline & $\begin{array}{l}\text { Nama pengguna } \\
\text { salah }\end{array}$ & $\begin{array}{l}\text { Tidak } \\
\text { berhasil }\end{array}$ & $\begin{array}{l}\text { Menampilkan pesan } \\
\text { peringatan kesalahan: } \\
\text { "identitas data tidak } \\
\text { cocok dengan data kami" }\end{array}$ \\
\hline & Kata sandi salah & $\begin{array}{l}\text { Tidak } \\
\text { berhasil }\end{array}$ & $\begin{array}{l}\text { Menampilkan pesan } \\
\text { peringatan kesalahan: } \\
\text { "identitas data tidak } \\
\text { cocok dengan data kami" }\end{array}$ \\
\hline & $\begin{array}{l}\text { Nama pengguna } \\
\text { dan kata sandi } \\
\text { benar }\end{array}$ & Berhasil & Masuk halaman utama \\
\hline
\end{tabular}

Kesalahan terjadi saat salah satu data yang dimasukkan salah atau kosong seperti yang dijelaskan pada Tabel 2 dan akan muncul peringatan kesalahan seperti pada gambar 6 berikut,

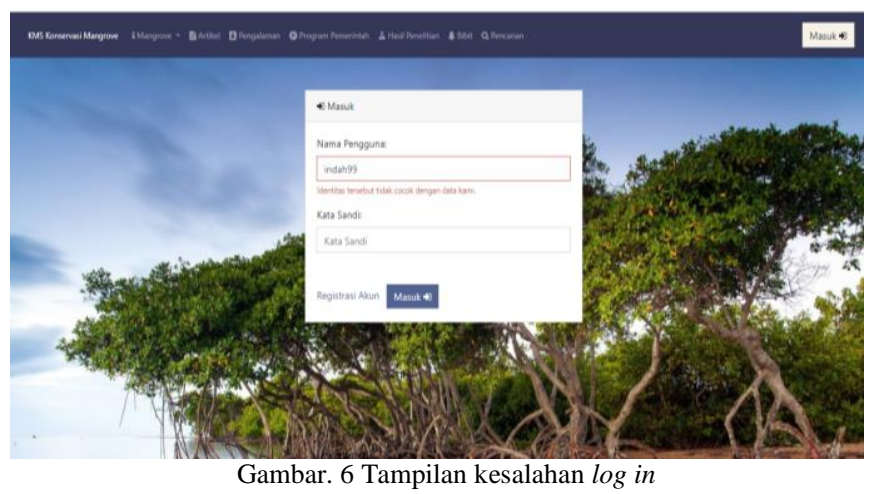

Kesalahan yang terjadi sudah ditangani pada kode program ystem ini, sehingga hanya akan muncul pesan kesalahan atau instruksi pengisian data. Dengan demikian, system dapat menangani data tersebut sesuai dengan apa yang diharapkan.

2) Pengujian User Acceptance Test (UAT): Pengujian User Acceptance Test (UAT) dilakukan dengan metode kuesioner yaitu dengan menyediakan beberapa pertanyaan serta jawaban. Kuesioner yang dilakukan melibatkan beberapa responden yang kualifikasinya telah ditentukan berdasarkan kebutuhan pengujian sistem. Responden adalah masyarakat, pemerintah dan peneliti yang merupakan aktor yang terlibat dengan konservasi mangrove. Jumlah responden yang akan melakukan pengujian ini adalah - sebanyak 20 orang, antara lain 4 orang dari pihak pemerintah, 2 orang peneliti, dan 14 orang masyarakat.

Beberapa aspek dalam pengujian yang dilakukan terhadap responden yaitu aspek kemudahan dan kegunaan. Kedua aspek tersebut menjadi poin utama penilaian yang akan diukur untuk mengetahui sejauh mana pengguna (responden) memberikan responnya atau feedback terhadap knowledge management system yang dibangun. Setiap aspek diukur berdasarkan range 1 hingga 5, yang dimaknai dari negatif ke positif. Sehingga angka 5 adalah angka maksimal dari setiap poin pada setiap aspek.

Selanjutnya aspek kemudahan meliputi pertanyaanpertanyaan yang terkait dengan pengalaman responden dalam menggunakan KMS, secara rinci pertanyaan-pertanyaan tersebut dapat dilihat pada Tabel 3.

TABEL IIIII

PERHITUNGAN ASPEK KEMUDAHAN

\begin{tabular}{|c|c|c|c|c|c|c|c|}
\hline \multirow[t]{2}{*}{ No } & \multirow{2}{*}{$\begin{array}{l}\text { Aspek } \\
\text { Kemudahan }\end{array}$} & \multicolumn{5}{|c|}{ Tanggapan } & \multirow{2}{*}{$\begin{array}{l}\text { Tot } \\
\text { al }\end{array}$} \\
\hline & & 1 & 2 & 3 & 4 & 5 & \\
\hline 1 & $\begin{array}{l}\text { Apakah informasi } \\
\text { mangrove yang } \\
\text { tersedia di dalam } \\
\text { sistem mudah } \\
\text { dipahami? }\end{array}$ & 0 & 0 & 0 & 6 & 14 & 20 \\
\hline 2 & $\begin{array}{l}\text { Apakah sistem } \\
\text { yang tersedia } \\
\text { dapat membantu } \\
\text { peran saudara } \\
\text { sebagai (peneliti, } \\
\text { petani/ } \\
\text { masyarakat)? }\end{array}$ & 0 & 0 & 2 & 7 & 11 & 20 \\
\hline 3 & $\begin{array}{l}\text { Apakah saudara } \\
\text { dapat melakukan } \\
\text { tambah, hapus, } \\
\text { dan edit pada } \\
\text { menu } \\
\text { pengalaman, } \\
\text { artikel dan hasil } \\
\text { penelitian dengan } \\
\text { mudah? }\end{array}$ & 0 & 1 & 0 & 12 & 7 & 20 \\
\hline \multicolumn{2}{|c|}{ Jumlah } & $\mathbf{0}$ & 1 & 2 & 25 & 32 & 60 \\
\hline \multicolumn{2}{|c|}{ Persentase (\%) } & $\mathbf{0}$ & 1,7 & 3,3 & 41,7 & 53,3 & 100 \\
\hline
\end{tabular}

Aspek kegunaan meliputi pertanyaan-pertanyaan yang terkait dengan pengalaman responden dalam menggunakan KMS, secara rinci pertanyaan-pertanyaan tersebut dapat dilihat pada Tabel 4.

TABEL IVV

PERHITUNGAN ASPEK KegunAAN

\begin{tabular}{|c|c|c|c|c|c|c|c|}
\hline \multirow[b]{2}{*}{ No } & \multirow{2}{*}{$\begin{array}{l}\text { Aspek } \\
\text { Kegunaan }\end{array}$} & \multicolumn{5}{|c|}{ Tanggapan } & \multirow[b]{2}{*}{ Total } \\
\hline & & 1 & 2 & 3 & 4 & 5 & \\
\hline 1 & $\begin{array}{l}\text { Apakah fasilitas } \\
\text { pencarian pada } \\
\text { sistem/ aplikasi } \\
\text { yang tersedia } \\
\text { dapat melakukan } \\
\text { pencarian dengan } \\
\text { tepat? }\end{array}$ & 0 & 0 & 3 & 11 & 6 & 20 \\
\hline 2 & $\begin{array}{l}\text { Bagaimana } \\
\text { tampilan awal } \\
\text { pada sistem? }\end{array}$ & 0 & 0 & 0 & 12 & 8 & 20 \\
\hline
\end{tabular}




\begin{tabular}{|l|l|l|l|l|l|l|l|}
\hline \multirow{2}{*}{ No } & $\begin{array}{l}\text { Aspek } \\
\text { Kegunaan }\end{array}$ & \multicolumn{2}{|l|}{ Tanggapan } & Total \\
\cline { 3 - 6 } & $\begin{array}{l}\text { Apakah fasilitas } \\
\text { tambah data pada } \\
\text { menu pengalaman } \\
\text { dan hasil } \\
\text { penelitian } \\
\text { berfungsi dengan } \\
\text { baik? }\end{array}$ & 0 & 0 & 4 & 11 & 5 & 20 \\
\hline 4 & $\begin{array}{l}\text { Bagaimana } \\
\text { menurut saudara } \\
\text { fitur-fitur yang } \\
\text { disediakan dalam } \\
\text { sistem? }\end{array}$ & 0 & 0 & 2 & 11 & 7 & 20 \\
\hline 5 & $\begin{array}{l}\text { Apakah informasi } \\
\text { yang disediakan } \\
\text { sudah memenuhi } \\
\text { kebutuhan } \\
\text { saudara? }\end{array}$ & 0 & 0 & 1 & 11 & 8 & 20 \\
\hline 6 & $\begin{array}{l}\text { Apakah tulisan } \\
\text { yang disediakan } \\
\text { pada website } \\
\text { dapat terbaca } \\
\text { dengan baik? }\end{array}$ & 0 & 0 & 0 & 7 & 13 & 20 \\
\hline 7 & $\begin{array}{l}\text { Bagaimana } \\
\text { kombinasi warna } \\
\text { pada web? }\end{array}$ & 0 & 0 & 1 & 12 & 7 & 20 \\
\hline 8 & $\begin{array}{l}\text { Apakah menurut } \\
\text { saudara melalui } \\
\text { menu pemerintah } \\
\text { pada aplikasi) } \\
\text { telah memenuhi } \\
\text { kebutuhan } \\
\text { minimal untuk } \\
\text { pelaksanaan } \\
\text { monitoring } \\
\text { pelaksanaan } \\
\text { program } \\
\text { konservasi hutan } \\
\text { mangrove? }\end{array}$ & 0 & 0 & 2 & 3 & 1 & 6 \\
\hline Jumlah & Persentase (\%) & & & & & & \\
\hline
\end{tabular}

Berdasarkan data dari responden di atas, maka selanjutnya yaitu mencari nilai persentase setiap aspek untuk mengetahui keberhasilan sistem. Perhitungan ini menggunakan rumus persentase,

$$
\begin{aligned}
\text { Persentase }(\%) & =\frac{\sum \text { Skor yong diperoleh }}{\text { Skor ideal }} \times 100 \% \\
& =266 /(5 \times 3 \times 20) \times 100 \% \\
& =88.7 \%
\end{aligned}
$$

Berikut data lengkap perhitungan, dapat dilihat pada tabel 5.

TABEL V

HASIL KUESIONER RESPONDEN TIAP ASPEK

\begin{tabular}{|l|l|}
\hline \multicolumn{1}{|c|}{ Aspek Penilaian } & \multicolumn{1}{c|}{ Responden (\%) } \\
\hline Kemudahan & 88,7 \\
\hline Kegunaan & 78,25 \\
\hline Total & 166,95 \\
\hline Rata-rata (\%) & 83.47 \\
\hline
\end{tabular}

Tabel di atas menunjukkan bahwa rata-rata skor ditinjau dari aspek kemudahan dari 20 responden yaitu memperoleh nilai rata-rata $88.7 \%$, berdasarkan aspek kegunaan dari 20 responden diperoleh nilai rata-rata $78.25 \%$. Adapun total ratarata seluruh aspek adalah $83.47 \%$. Persentase untuk mengetahui hasil akhir dari pengujian, dilakukan dengan pencarian interval. Berikut merupakan tabel persentase interval.

TABEL VI

PERSENTASE INTERVAL

\begin{tabular}{|l|l|}
\hline Persentase (\%) & Keterangan \\
\hline $0 \%-19,99 \%$ & Sangat tidak (mudah, membantu) \\
\hline $20 \%-39,99 \%$ & Tidak (mudah, membantu) \\
\hline $40 \%-59,99 \%$ & Cukup (mudah, membantu) \\
\hline $60 \%-79,99 \%$ & Mudah, membantu \\
\hline $80 \%-100 \%$ & Sangat (mudah, membantu) \\
\hline
\end{tabular}

Berdasarkan hasil rata-rata persentase diatas dapat disimpulkan bahwa sistem yang dibangun sangat membantu dan sangat mudah digunakan.

\section{KESIMPULAN}

Penelitian yang dilakukan berfokus pada KMS dan konservasi hutan mangrove di mana hutan mangrove sebagai objeknya. Literatur review dilakukan untuk membantu dalam memahami tiga proses utama yang terjadi pada konservasi mangrove yaitu pembibitan, penanaman, dan perawatan. KMS mendukung konservasi hutan mangrove dengan data-data untuk mengatasi permasalahan yang terjadi. KMS membantu dalam mengidentifikasi, membagi, dan mengevaluasi informasi yang didapat. Identifikasi masalah dilakukan untuk mengetahui masalah yang terjadi dan bagaimana cara untuk menangani permasalahan tersebut. Setelah identifikasi maka dilakukan analisis. Analisis kebutuhan sistem dilakukan untuk mengetahui yang diperlukan pada proses konservasi mangrove, peran aktor, data yang digunakan.

Perancangan KMS dibuat berdasarkan analisis kebutuhan yang sudah dilakukan. Perancangan KMS dilakukan terdiri dari arsitektur KMS secara umum dan framework KMS dengan empat tahapan yang dilakukan yaitu analisis, strategi, perencanaan, dan eksekusi. Empat tahapan inilah yang menjadi acuan dalam pembuatan KMS Hutan Mangrove. Perancangan UML yang digunakan terdiri dari tiga diagram, digambarkan dalam bentuk class diagram untuk menggambarkan suatu struktur sistem yang akan dibangun dan hubungan antar tabel, use case diagram untuk mendeskripsikan fungsi apa saja yang ada di dalam sistem dan siapa saja yang berhak menggunakan fungsi-fungsi itu dan activity diagram untuk menggambarkan aktivitas yang dapat dilakukan oleh sistem bukan proses yang dilakukan aktor terhadap sistem.

Penelitian ini menggunakan pengujian black box dan pengujian UAT dengan metode kuesioner. Hasil dari pengujian black box yang dilakukan memberikan hasil bahwa input dan output data yang dilakukan sesuai dan sistem dapat merespon hasil dari input data yang dilakukan jika suda benar atau terjadi kesalahan. Hasil kuesioner yang dilakukan $83.47 \%$ menyatakan aplikasi ini sangat membantu dalam memberikan informasi dan pengetahuan serta sangat mudah dalam penggunaan aplikasi. 
Melalui penelitian ini, dapat dikatakan bahwa KMS bisa membantu proses sharing informasi. KMS hutan mangrove menjadi tepat untuk melakukan pengelolaan maupun manajemen data. KMS akan menjadi sumber pengetahuan yang tepat khususnya pada pembahasan proses konservasi hutan mangrove.

\section{REFERENSI}

[1] M. Fikriyani, "Evaluasi Program Rehabilitasi Mangrove di Pesisir Desa Bedono Kecamatan Sayung Kabupaten Demak," Ruang, vol. 2, no. 1, pp. 81-90, 2013.

[2] I. Majid, M. H. I. Al Muhdar, F. Rohman, and I. Syamsuri, "Konservasi Hutan Mangrove di Pesisir Pantai Kota Ternate Terintegrasi dengan Kurikulum sekolah," BIOEDUKASI, vol. 4, no. 2, 2016.

[3] S. P. Harianto, "Konservasi Mangrove dan Potensi Pencemaran Teluk Lampung," J. Manaj. Kualitas Lingkung., vol. 1, no. 1, pp. 9-15, 1999.

[4] I. Nonaka and H. Takeuchi, "The Knowledge Creating Company: How Japanese Create the Dynamics of Innovation. 1995." New York: Oxford University Press

[5] P. L. Tobing, "Knowledge Management: Konsep, Arsitektur dan Implementasi," Yogyakarta Graha Ilmu, 2007.

[6] C. W. Holsapple and K. D. Joshi, "Description and Analysis of Existing Knowledge Management Frameworks," in Proceedings of the 32nd Annual Hawaii International Conference on Systems Sciences. 1999. HICSS-32. Abstracts and CD-ROM of Full Papers, 1999, pp. 15pp.

[7] R. Maier and T. Hadrich, "Knowledge Management Systems," in Encyclopedia of Knowledge Management, Second Edition, IGI Global, 2011, pp. 779-790.

[8] Y. R. Noor, M. Khazali, and S. I NN, Panduan Pengenalan Mangrove di Indonesia. PKA/WI-IP (Wetlands International-Indonesia Programme), 1999.

[9] I. J. Dewanto, "System Development Life Cycle Dengan Beberapa Pendekatan," J. FASILKOM, vol. 2, no. 1, pp. 39-47, 2004

[10] M. S. Mustaqbal, R. F. Firdaus, and H. Rahmadi, "Pengujian Aplikas Menggunakan Black Box Testing Boundary Value Analysis," J. Ilm. Teknol. Inf. Terap., vol. 1, no. 3, 2016.

[11] A. S. Rosa, "Rekayasa Perangkat Lunak Terstruktur dan Berorientasi Objek," 2016

[12] B. Sidik, "User Acceptance Test." Online, 2006

[13] D. Yona, N. Hidayati, S. H. J. Sari, I. N. Amar, and K. W. Sesanty, "TEKNIK PEMBIBITAN DAN PENANAMAN MANGROVE DI BANYUURIP MANGROVE CENTER, DESA BANYUURIP, KECAMATAN UJUNGPANGKAH, KABUPATEN GRESIK," $J$ Dinamika, vol. 3, no. 1, 2018.

[14] Patang, "Analisis Strategi Pengelolaan Hutan Mangrove (Kasus D Desa Tongke-Tongke Kabutapen Sinjai)," J. Agrisistem, vol. 8, 2017.

[15] M. Khazali and I. Programme, "Panduan Teknis Penanaman Mangrove," no. April 1999, 2005. 